\title{
Maternal Diabetes Mellitus - Risk Factor for Fetus and Infant
}

\author{
Lorenc A*, Otto-Buczkowska E \\ Medical Specialist Centre in Gliwice, Poland
}

Received: May 24, 2018; Accepted: June 22,2018; Published:June 28,2018

*Corresponding author: Lorenc Anna, Medical Specialist Centre in Gliwice, Poland; E-mail: a.lorenc89@gmail.com

\begin{abstract}
Diabetes during pregnancy may occur as pregestational or gestational diabetes mellitus. Throughout gestation there is a close relationship between maternal and fetal blood glucose concentrations. Maternal hyperglycemia leads to hyperglycemia of the fetus, stimulating the fetal pancreas to synthesize excessive amounts of insulin. At the time of delivery, after separation of the placenta, the flow of glucose to the newborn that is appropriate for hyperglycemia is suddenly interrupted. Excessive insulin production in the fetus in response to maternal hyperglycemia can cause severe hypoglycaemia during the neonatal period. It is a very common complication of maternal diabetes. In healthy children during the first 4-6 postnatal hours there is a physiological decrease in glucose level from the mother's blood level to about $2.5 \mathrm{mmol} / \mathrm{l}$ ( $45 \mathrm{mg} / \mathrm{dl}$ ). This is related to still not fully developed adaptive mechanisms. There is strong evidence that good glycemic control is essential for an optimal outcome of pregnancy in diabetic women.
\end{abstract}

Despite advances in perinatal care, infants of diabetic mothers remain at risk for a multitude of physiologic, metabolic, and congenital complications such as preterm birth, macrosomia, respiratory distress, hypoglycemia, hypocalcemia, hyperbilirubinemia, hypertrophic cardiomyopathy, and congenital anomalies, particularly of the central nervous system.

Keywords: Pregestational Diabetes; Gestational Diabetes; Glycemic Control; Glucose Level; Macrosomia; Microsomia; Hypoglycaemia

\section{Introduction}

The first reports of diabetes during gestation come from the nineteenth century. In 1824 Heinrich Gottlieb Bennewitz in his doctoral dissertation described a pregnancy complicated by polydipsia, polyuria and progressive weakening in a young, healthy woman. The ailments appeared in her fifth pregnancy and subsided after childbirth. There was sugar found in the urine of the pregnant woman. The child, weighing over $6 \mathrm{~kg}$, died during labour. In 1882 at the London Society of Obstetricians Matthew Duncan presented the course of 22 pregnancies in 15 diabetic women. 13 fetuses died intrauterinally and 9 women died within one year of the termination of pregnancy. It was only the discovery by Banting and Best in 1922 and the introduction of insulin treatment that gave the chance to prolong the life of patients with diabetes, including pregnant women. [1]
Systematic research on gestational diabetes began in the 1940s. In 1954, the term "meta gestational diabetes" was first used, suggesting the transient nature of the disorder. In 1964 O'Sullivan and Mahan proposed diagnostic criteria for gestational diabetes. In 1979 gestational diabetes acquired a formal definition: 'Carbohydrate intolerance of variable severity recognized for the first time in pregnancy' and became established as a distinct form of Diabetes.[2]

One year later (1980), Freinkel hypothesized that fetal development depends not only on maternal hyperglycemia but also on its severity and on the stage of pregnancy when it occurs. The first Polish analysis of the fate of children born to diabetic mothers was presented in 1972. [3]

\section{Maternal diabetes}

Throughout gestation we may be dealing with varying degrees of glucose homeostasis disorders. This may be clinically manifested diabetes mellitus in patients with pre-existing diabetes (PGDM: pregestational diabetes mellitus) or gestational diabetes mellitus (GDM), which occurred already during pregnancy.

Pregestational diabetes can be autoimmune diabetes, including both 'classic' type 1 diabetes and LADA (Latent Autoimmune Diabetes in Adults) as well as type 2 diabetes and rarely occurring MODY (Maturity Onset Diabetes of the Young).

Gestational diabetes mellitus can also be the first manifestation of the abovementioned forms. (4) According to the current recommendations, all pregnant women should be diagnosed for glucose tolerance disorders. There are established procedures for patients with pregestational diabetes. It is most desirable when their pregnancy is planned and preceded by careful preparation of the patient for pregnancy. Such patients already in the planning period of pregnancy should be covered with specialised medical units' care.

A literature review by the Danish authors indicated that the incidence of preeclampsia in women with diagnosed type 1 diabetes was 5-6 times more common in relation to the population. [5]

Pre-existing hypertension and high blood pressure within the Normotensive range as well as presence of microangiopathy were predictors of preeclampsia. 
Other authors also point out that non-optimal control of metabolic parameters is a significant risk factor for women with PGDM. [6]

\section{Gestational diabetes mellitus}

It is carbohydrate intolerance occurring during pregnancy. Although it is characterized by greater insulin resistance, little is known about the underlying cellular mechanisms of GDM.

Risk factors for the development of gestational diabetes are the mother's age, history of macrosomia (birth weight $>4000$ g) previous delivery of a neonate with a congenital anomaly, hypertension, overweight or obesity, family history of diabetes type 2, gestational diabetes during previous pregnancies, polycystic ovary syndrome.

The relation between the incidence of GDM and elevated oxidative stress due to overproduction of reactive oxygen species (ROS) was emphasized by Witczak et al. [7] The aim of the study was to determine the prevalence of structural aberrations (CA) in peripheral blood of pregnant women with GDM and umbilical cord blood in neonates.

Recent studies of Polish authors have shown that different inflammatory mediators are considered risk factors leading to the development of GDM. [8] The authors demonstrated that polymorphisms pro-inflammatory IL18 cytokines may be associated with increased risk of GDM. Among the risk factors for GDM development, the deficiency in 25-hydroxyvitamin D[25 $(\mathrm{OH}) \mathrm{D}]$ is recently mentioned more and more often. $[9,10,11]$

However, data on the role of vitamin D in the regulation of glucose homeostasis during pregnancy and the impact of its shortage on the risk of developing gestational diabetes require further research.

Recently, Danish authors have reported a study of 198 pregnant women with type 1 diabetes; in the research group, insufficient vitamin D intake $(<50 \mathrm{nmol} / \mathrm{l})$ was observed in as many as 68 women (34\%). [12] Vitamin D supplementation of $1500-2000 \mathrm{IU} / \mathrm{d}$ is recommended. [13]

\section{Diagnosing gestational diabetes}

The American Diabetes Association (ADA) recommends three different ways to diagnose gestational diabetes. [16] Preliminary diagnosis should be made at the beginning of pregnancy, during the first visit to the gynaecologist. The glucose tolerance test (OGTT) should be performed between 24 and 28 weeks of gestation. In pregnant women from risk groups, the test should be performed early in pregnancy.

Sugar levels in the oral glucose tolerance test indicating the diagnosis of gestational diabetes are [17]:

- fasting plasma glucose 5.1-6.9 mmol/l (92 -125 mg/dl);

- 1-hour plasma glucose $\geq 10.0 \mathrm{mmol} / \mathrm{l}$ (180 mg/dl) following a $75 \mathrm{~g}$ oral glucose load and

- 2-hour plasma glucose 8.5-11.0 mmol/l (153 -199 mg/dl) following a $75 \mathrm{~g}$ oral glucose load.
Zawiejska et al emphasized the usefulness of fasting hyperglycemia measurements in mothers with significantly increased risk of perinatal complications. [18]

Similar observations were made by Dielmis et al. [19] The authors found that women with FPG levels of 5.1-5.5 mmol/l $(91.8-99.0 \mathrm{mg} / \mathrm{dl})$ had an increased risk of adverse maternal and perinatal outcome, although they would not be diagnosed with GDM according to NICE criteria. Other authors point to the utility of glucose measurements OGTT in 1 hour after a glucose load in predicting the development of diabetes mellitus. [20]

Currently, more and more attention is being paid to the presence of glucose homeostasis disorders in pregnant women, which, according to the current criteria, are not considered to be gestational diabetes. However, the studies show that even a small degree of hyperglycemia during pregnancy increases the risk of obstetric and neonatal complications.

The basis for the monitoring of glucose metabolism in pregnant women is carefully conducted self-monitoring. In pregnant women with pregestational diabetes mellitus these self-monitoring rules are set individually and must be adjusted to intensive insulin therapy.

In patients with gestational diabetes self-monitoring includes: glucose measurements (usually 5-6 times a day), testing for ketone bodies and glucose in urine (in justified cases: weight loss or high blood glucose levels).

More and more attention is paid to the use of modern techniques for monitoring glucose levels during pregnancy. [21]

Moy et al presented an analysis of the results of the use of different methods of self-monitoring of blood glucose concentration in the treatment of diabetes during pregnancy. [22] The analysis involved 538 women with type 1 and type 2 diabetes. In this review, the authors did not find any clear evidence that any glucose monitoring technique was superior to any other technique in pregnant women with pre-existing type 1 or type 2 diabetes. The authors believe that further research is necessary.

When discussing disorders of glucose metabolism during pregnancy, the need to monitor the thyroid function is also worth mentioning, because dysfunction of the thyroid is a phenomenon often associated with these disorders. [23]

It is also very important to control weight gain in pregnant women. [24]

Gutaj et al conducted a retrospective analysis of 209 overweight and obese pregnant women with gestational diabetes. They found that increased pregestational BMI played a role in predicting birth weight greater than $4300 \mathrm{~g}$, pregnancy-induced hypertension and the number of pregnancies terminated with caesarean section. [25]

Many authors stress the need to prevent excessive weight gain during pregnancy. [26] The degree of complication related to the fetus is primarily dependent on the time of diagnosis of diabetes, and hence on the duration of fetal exposure to high glucose concentration. [27,28,29] 
Hyperglycemia in the first 8-10 weeks of fetal development is the cause of miscarriages, intrauterine deaths and developmental abnormalities in the offspring. Untreated gestational diabetes results in up to $30 \%$ increase in perinatal mortality. The last 30 years have brought tremendous progress in the care of a pregnant woman suffering from diabetes as well as her child, both during its fetal life and during the perinatal period. This allowed for dramatic reduction in the risk of fetal damage and significantly reduced the number of failed pregnancies. However, even very carefully monitored pregnancy in a diabetic patient carries many risks for the baby, both in fetal and postnatal life.

The most significant progress in recent years in the course and outcomes of pregnancies complicated by diabetes is evident in the decline in perinatal mortality, understood as intrauterine and neonatal deaths.

Childbirths in diabetic women should take place in specialist centres with intensive care units for new-borns. The newborn of a diabetic mother is always a child of special risk and as such requires special care in the perinatal period. Hyperglycemia during pregnancy, especially at its early stage, is considered to be a very serious risk factor for fetal defects, regardless of the type of diabetes. [30,31]

Gruszka et al. presented the results of the study in a group of 300 pregnant women with GDM. [32] According to these authors, maternal body mass index correlated significantly with fetal macrosomia, which significantly influenced the method of termination of pregnancy and neonatal status at birth. $[33,34$, $35,36]$

\section{Fetal growth disorders}

Hyperglycemia of pregnant women and fetal hyperinsulinism are the major determinants of macrosomia (LGA: large for gestational age) of newborn which is a significant risk factor for obstetric complications. [37,38] It is defined as the birth weight> 90 centile in relation to the standards adopted for gestational age.

In the offspring of diabetic mothers there is asymmetric macrosomia in which, apart from body weight gain and increased volume of adipose tissue, there are changes in body proportions in the form of increased shoulder and abdominal circumferences and decrease in the ratio of the head circumference to the chest circumference. The prevalence of fetal macrosomia in the general population is $8-14 \%$, and in women with diabetes it varies between $25-42 \%$. [39,40]

Hyperinsulinism, which results from excessive stimulation of the fetal $\beta$ cells by the excessive amounts of glucose coming through the placenta, is regarded to be the main cause of macrosomia. It results in fetal hyperinsulinemia. Hyperglycemia and hyperinsulinemia stimulate the process of lipogenesis and hyperplasia of adipose tissue. Excessive growth occurs mainly in organs and tissues the metabolism of which is insulin-dependent, including liver, spleen and heart, adipose tissue and muscle tissue.

Another fetal malformation in pregnancy complicated by gestational diabetes mellitus can be SGA ( small for gestational age), birth weight $<10$ th percentile for gestational age which may be caused by excessive reduction in maternal glycemia, although recurrent hypoglycemia in the mother may paradoxically result in macrosomal onset due to hyperinsulinemia stimulated by glucose taken by the mother. [41]

Fetal hypotrophy is defined as the fetal body weight below 10 centile (in respect to fetal age and gender). There are many factors that may affect fetal growth restriction, including changes in the concentration of placental growth factor (PIGF). [42]

Intrauterine hypotrophy occurs in children of mothers who have been suffering from diabetes for a long time and who experience vascular complications. Hypotrophy is most commonly asymmetrical in nature (body length and head circumference correspond to fetal age, while body mass is too lo w).

During the perinatal period, the newborn may also have a number of other disorders threatening its life and health. For prevention of these disorders, it is of utmost importance to have a thorough metabolic control of diabetes during pregnancy and childbirth.

The consequence of gestational diabetes can be a breathing disorder in the newborn (RDS: respiratory distress syndrome). It is the result of a deficiency of surface agent, often accompanied by patent ductus arteriosus. The proceeding is similar to the incidence of the syndrome in other states. These children unconditionally require hospitalization in the intensive care unit. Its manifestation in the cardiovascular system may be diabetic cardiomyopathy.

Incorrect metabolic control of diabetes in pregnant women leads to a number of neonatal biochemical disorders such as hypoglycemia, hyperbilirubinemia, hypocalcemia or hypomagnesemia. Even very mild changes in glucose tolerance can lead to excessive or disharmonious fetal growth.

\section{Hypoglycemia}

Hypoglycemia in the newborn is diagnosed when the blood glucose level is below $30-40 \mathrm{mg} / \mathrm{dl}$. (1.7-2.2 mmol/l). Hypoglycaemia is one of the most frequent metabolic problems in neonatal medicine and maintaining glucose homeostasis. The maximum intensity of this phenomenon is observed between 1 and 3 hours of life. It occurs in $10-60 \%$ of the newborns of mothers suffering from diabetes mellitus. Hypoglycemia in the neonate is a common complication in both pregestational and gestational diabetes mellitus.

The issue of assessing blood glucose levels in newborns and young infants raises a lot of controversy. It is still not known exactly when the concentration should be considered normal and when it is already hypoglycaemia. [43,44,45]

The result of this glucose test depends on many factors. There are very important factors related to the examined newborn, i.e the time from the birth, the course of the labour (hypoxia, etc.), the newborn's body weight in relations to the gestational age (LGA, SGA) as well as maternal factors. Recently, continuous monitoring (CGMS: continuous glucose monitoring sensor) is used more and more frequently to monitor glycemia, also in the 
case of newborns and infants. [46,47]

It is assumed that normal serum glucose level in neonates who do not receive intravenous infusions should be within the range of $50-100 \mathrm{mg} / \mathrm{dl}(2.8-5.6 \mathrm{mmol} / \mathrm{l})$.

\section{Hypocalcemia}

Hypocalcemia is recognized when the total calcium level drops below $7 \mathrm{mg} / \mathrm{dl}(1.75 \mathrm{mmol} / \mathrm{l})$ or in case of the ionized calcium level - below $0.87 \mathrm{mmol} / \mathrm{l}$. The lowest values are observed in the first 24-72 hours of life. The intensity of hypocalcemia is proportional to the severity of diabetes mellitus in the mother.

\section{Hypomagnesaemia}

Hypomagnesaemia is diagnosed with serum magnesium level below $1.6 \mathrm{mg} / \mathrm{dl}(0.6 \mathrm{mmol} / \mathrm{l})$

\section{Hyperbilirubinemia}

Hyperbilirubinemia (bilirubin greater than $15 \mathrm{mg} \%$ ) is observed in approximately $20 \%$ of neonates with diabetes complications.

Undoubtedly, all complications of gestational diabetes are linked to glycemic control. Thus, to minimize the risks, it is necessary to have very strict metabolic control in the mother throughout the pregnancy, up to delivery.

After the birth of a child of the diabetic mother, the newborn should be treated with special care. The clinical condition of the newborn baby must be assessed very carefully and its vital functions in the first days after birth should be monitored thoroughly.

\section{Treatment of a diabetic pregnant woman}

Hypoglycemia. To maintain glucose homeostasis, it is of fundamental importance to maintain a good relationship between insulin and glucagon secretion in the first hours after birth. The superiority of glucagon secretion is essential to protect the newborn from severe hypoglycemia immediately after birth. $[56,57,58]$ In the neonates of diabetic mothers, these mechanisms may be impaired.

Excessive insulin production in the fetus in response to maternal hyperglycemia may cause severe hypoglycemia in the neonatal period. Some authors believe that even asymptomatic hypoglycemia in the newborn can cause CNS damage; hence careful monitoring of glycemia in neonates from diabetic pregnancies is necessary. [44] It is necessary to monitor glycemia by measuring its value at 30-minute intervals for the first 2 hours after childbirth, then at intervals of 2-4 hours in the first $24-48$ hours.

It is advisable to maintain blood glucose levels within the range of $60-150 \mathrm{mg} / \mathrm{dl}(3.3-8.3 \mathrm{mmol} / \mathrm{l})$. If blood glucose concentration immediately after birth is $\geq 40 \mathrm{mg} / \mathrm{dl}$ ( $\geq 2.2 \mathrm{mmol} / \mathrm{l})$ and the general condition of the baby is good, it is generally sufficient to start feeding early or possibly orally administer $10 \%$ glucose in the first 30-60 minutes after birth. If blood glucose concentration is $<30 \mathrm{mg} / \mathrm{dl}(1.7 \mathrm{mmol} / \mathrm{l})$ or if blood glucose is $<45 \mathrm{mg} \%$ but clinical symptoms of hypoglycemia are present, glucose intravenous infusion should be started with $2 \mathrm{ml} / \mathrm{kg}$ of $10 \%$ glucose for $2-3$ minutes, then 6 to $8 \mathrm{mg}$ glucose $/ \mathrm{kg} / \mathrm{min}$ (3.6-4.8 $\mathrm{ml} \mathrm{10 \%} \mathrm{glucose} / \mathrm{kg} / \mathrm{hr}$ ) up to a total of $80-120 \mathrm{ml} 10 \%$ glucose $/ \mathrm{kg} /$ day. If blood glucose concentration $>150 \mathrm{mg} / \mathrm{dl}$ (> 8.3 $\mathrm{mmol} / \mathrm{l}$ ), the infusion should be slowed down. Sometimes higher doses of glucose $(8-12 \mathrm{mg} / \mathrm{kg} / \mathrm{min})$ and more concentrated glucose solutions are needed, in such cases access to the central vein is necessary. In particularly refractory cases, glucagon must be administered (30 $\mu \mathrm{g} / \mathrm{kg}$, not exceeding a dose of $1 \mathrm{mg}$ ).

The need for high glucose concentrations indicates hyperinsulinism and is an indication for steroids or diazoxide administration.

\section{Other metabolic disorders worth mentioning include}

* Hypocalcemia which usually has no symptoms and undergoes spontaneous normalization. Sometimes, however, intravenous infusion of $10 \%$ Calcium gluconicum in glucose solution may be required, an extended infusion may be necessary when clinical symptoms persist;

*Hypomagnesemia which requires adjustment if serum magnesium concentration is $<0.6 \mathrm{mmol}$ / l by administration of $0.1-0.3 \mathrm{ml} / \mathrm{kg} 50 \%$ magnesium sulphate solution;

* Polycythemia which is compensated by administration of $5 \%$ albumin or an exsanguination transfusion if peripheral vein haematocrit > 65\%;

* Hyperbilirubinemia - the treatment of which should be implemented if serum bilirubin levels exceed $15 \mathrm{mg} / \mathrm{dl}$.

\section{Conclusion}

The threat to the fetus is not only hyper- but also hypoglycaemia. Maternal hyperglycemia may cause excessive fetal growth (macrosomia or LGA, i.e. higher than the original birth weight due). Maternal hypoglycemia poses a risk of microsomia or SGA, i.e. a lower than expected birth weight of a newborn, although recurrent hypoglycaemia in the mother may paradoxically result in macrosomia due to hyperinsulinemia stimulated by mother glucose. After pregnancy complicated with gestational diabetes mellitus, sugar levels generally return to normal, just a few days after childbirth. It must be borne in mind that the history of gestational diabetes is a risk factor for the development of diabetes in the future as well as the recurrence of this complication in the subsequent pregnancy. $[59,60]$

It is therefore recommended to perform a glucose tolerance check 6-12 weeks after the childbirth and then control it, depending on the indications, every 1-2-3 years. It is very important to take the glucose tolerance test before the next planned pregnancy. It is also important to prevent the onset of glucose metabolism disorders through very careful weight control, proper diet and physical activity. Maternal overweight and obesity are the most important factors causing perinatal complications. 


\section{References}

1. Cundy T, Holt RI. Gestational diabetes: paradigm lost? Diabet Med. 2017;34(1):8-13. Doi: 10.1111/dme.13200

2. American Diabetes Association Workshop-Conference on gestational diabetes: summary and recommendations. Diabetes Care. 1980;3(3):499-501.

3. Otto Buczkowska E, Ochabska Z, Sońta Jakimczyk D, Piasecki M. Fate of children born to mothers with diabetes mellitus. XXI Scientific Conference of the Diabetes Section. Polish Society of Internal Medicine - Łódź 1972.

4. Chwalba A, Otto-Buczkowska E. Gestational Diabetes: Diagnosis of Diabetes Type LADA (Latent Auto immunological Diabetes in Adults). in Gestational Diabetes: Risk Factors, Management and Outcomes. Coleman I. [ed], Ch 2 . 2017; Nova Science Publisher: Hauppauge NY, USA.

5. Vestgaard M, Sommer MC, Ringholm L, Damm P, Mathiesen ER. Prediction of preeclampsia in type 1 diabetes in early pregnancy by clinical predictors: a systematic review. J Matern Fetal Neonatal Med.2018;31(14):1933-1939. Doi: 10.1080/14767058.2017.1331429

6. Gutaj P, Zawiejska A, WenderOżegowska E, Brązert J. Maternal factors predictive of firsttrimester pregnancy loss in women with pregestational diabetes. Pol Arch Med Wewn. 2013;123(1-2):21-28

7. Witczak M, Wilczyński J, Gulczyńska E, Talar T, Mordalska A, Łopaczyńska D, Ferenc T. What is the impact of gestational diabetes mellitus on frequency of structural chromosome aberrations in pregnant women and their offspring? Mutat Res. 2017;818:27-30. Doi: 10.1016/j.mrgentox.2017.04.003

8. Tarnowski M, Wieczorek A, Dziedziejko V, Safranow K, Ustianowski $\mathrm{P}$, Celewicz Z, et al. IL16 and IL18 gene polymorphisms in women with gestational diabetes. Ginekol Pol. 2017;88(5):249-254. Doi: 10.5603/GP.a2017.0047

9. Otto-Buczkowska E, Chwalba A. vitamin D in disorders of glucose metabolism Forum Med Rodz. 2017;11(2):47-53

10. Parlea L, Bromberg IL, Feig DS, Vieth R, Merman E, Lipscombe LL. Association between serum 25-hydroxyvitamin D in early pregnancy and risk of gestational diabetes mellitus. Diabet Med. 2012;29(7): e25-e32. Doi: 10.1111/j.1464-5491.2011.03550.x

11. Triunfo S, Lanzone A, Lindqvist PG. Low maternal circulating levels of vitamin $\mathrm{D}$ as potential determinant in the development of gestational diabetes mellitus. JEndocrinol Invest. 2017;40(10):10491059. Doi: 10.1007/s40618-017-0696-9.

12.Vestgaard M, Secher AL, Ringholm L, Jensen JB, Damm P, Mathiesen ER. Vitamin D insufficiency, preterm delivery and preeclampsia in women with type 1 diabetes - an observational study. Acta Obstet Gynecol Scand. 2017;96(10):1197-1204. Doi: 10.1111/aogs.13180
13. Holick MF, Binkley NC, Bischoff-Ferrari HA, Gordon CM, Hanley DA, Heaney RP. et al. Evaluation, treatment, and prevention of vitamin D deficiency: an Endocrine Society clinical practice guideline. J Clin Endocrinol Metab. 2011; 96(7):1911-1930. Doi: 10.1210/jc.20110385

14. Soheilykhah S, Mojibian M, Jannati Moghadam M. Serum ferritin concentration in early pregnancy and risk of subsequent development of gestational diabetes: A prospective study. Int J Reprod Biomed (Yazd). 2017;15(3):155-160.

15.Wójcik M, Chmielewska-Kassassir M, Grzywnowicz K, Woźniak L, Cypryk K. The relationship between adipose tissue-derived hormones and gestational diabetes mellitus (GDM). Pol JEndocrinol 2014;65(2):134-142. Doi: 10.5603/EP.2014.0019

16.American Diabetes Association. Classification and diagnosis of diabetes. Diabetes Care 2016;39(Suppl. 1):S13-S22. Doi: 10.2337/ dc16-S005

17. Guidelines on the management of diabetic patients. A position of Diabetes Poland. Clin Diabet 2018;7(1):1-90. Doi: 10.5603 / DK.2018.0001

18.Zawiejska A, Wender-Ożegowska E, Radzicka S, Brązert J. Maternal hyperglycemia according to IADPSG criteria as a predictor of perinatal complications in women with gestational diabetes: a retrospective observational study. J Matern Fetal Neonatal Med 2014;15:1526-1530. Doi: 10.3109/14767058.2013.863866

19. Djelmis J, Pavić M, Mulliqi Kotori V, Pavlić Renar I, Ivanisevic M, Oreskovic S. Prevalence of gestational diabetes mellitus according to IADPSG and NICE criteria. Int J Gynaecol Obstet. 2016;135(3):250 254. Doi: 10.1016/j.ijgo.2016.07.005

20.0tto-Buczkowska E, Dryżałowski M. The utility of serum glucose measurement at 1 hour of the oral glucose tolerance test. Clinical Diabetology. 2016;5(4):127-130

21. Polsky S, Garcetti R.See comment in PubMed Commons below CGM, Pregnancy, and Remote Monitoring. Diabetes Technol Ther. 2017;19(S3):S49-S59. Doi: 10.1089/dia.2017.0023

22. Moy FM, Ray A, Buckley BS, West HM. Techniques of monitoring blood glucose during pregnancy for women with pre-existing diabetes. Cochrane Database Syst Rev. 2014;30(4):CD009613. Doi: 10.1002/14651858.CD009613

23.Otto-Buczkowska E, Tucholski K. Thyroid dysfunction and disorders of carbohydrate metabolism during pregnancy. Med Metabol 2014;18:68-71

24.Boriboonhirunsarn D, Kasempipatchai V. Incidence of large for gestational age infants when gestational diabetes mellitus is diagnosed early and late in pregnancy, J Obstet Gynaecol Res. 2016;42(3):273-278. Doi: 10.1111/jog.12914 
25.Gutaj P, Wender-Ozegowska E, Mantaj U, Zawiejska A, Brazert J. [Maternal body mass index and gestational weight gain and their association with perinatal outcome in women with gestational diabetes]. Ginekol Pol. 2011;82(11):827-833.

26. Muktabhant B, Lawrie TA, Lumbiganon P, Laopaiboon M. Diet or exercise, or both, for preventing excessive weight gain in pregnancy. Cochrane Database Syst Rev. 2015;(6):CD007145. Doi: 10.1002/14651858.CD007145

27. Cypryk K, Wender-Ożegowska E, Kosiński M. Bartyzel $€$, Olejniczak D, CzajkowskiK. et al. [Analysis of maternal factors and pregnancy outcomes in women with gestational diabetes mellitus. Results of the scientific and educational programme "We care for the Mothers"] Diabet. Clin. 2014:3(4):144-156

28.Pawlik D, Radziszewska R. [The maternal diabetes mellitus and consequences for newborn] Pediatr. Endocrinol. 2015;14:43-51.

29. Walicka M, Czerwińska E, Marcinowska-Suchowierska E. [Diabetes and pregnancy.] Progress in Medicine 2010;23(5):360-368.

30. Meek CL, Lewis HB, Patient C, Murphy HR, Simmons D. Diagnosis of gestational diabetes mellitus: falling through the net. Diabetologia. 2015;58(9):2003-2012. Doi: 10.1007/s00125-015-3647-z

31. Metzger BE, Persson B, Lowe LP, Dyer AR, Cruickshank JK, Deerochanawong C, Halliday $\mathrm{HL}$, et al. Hyperglycemia and adverse pregnancy outcome study: neonatal glycemia. Pediatrics. 2010;126(6):e1545-e1552. Doi: 10.1542/peds.2009-2257

32.Gruszka A, Adamczyk-Gruszka 0, Lewandowska-Andruszuk I, Siennicka M, Gruszka J. Gestational diabetes mellitus: the effects of diagnosis time and implementation of diabetic care on management of glycemia. Medical Studies 014;30(2):99-105. Doi: 10.5114/ ms.2014.43601

33. Kawakita T, Bowers K, McWhorter K, Rosen B, Adams M, Miodovnik $M$, et al. Characterizing Gestational Weight Gain According to Institute of Medicine Guidelines in Women with Type 1 Diabetes Mellitus: Association with Maternal and Perinatal Outcome. Am J Perinatol. 2016;33(13):1266-1272. Doi: 10.1055/s-0036-1585420

34. Mitanchez D, Burguet A, Simeoni U. Infants born to mothers with gestational diabetes mellitus: mild neonatal effects, a longterm threat to global health. J Pediatr. 2014;164(3):445-450. Doi: 10.1016/j.jpeds.2013.10.076

35. Scholtens DM, Bain JR, Reisetter AC, Muehlbauer MJ, Nodzenski M, Stevens RD, et al. Metabolic networks and metabolites underlie associations between maternal glucose during pregnancy and newborn size at birth. Diabetes. 2016;65(7):2039-2050. Doi: $10.2337 / \mathrm{db} 15-1748$

36.Zamłyński J, Olejek A, Wiecek A, Mańka G, Chudek J, Bodzek P, et al. The influence of metabolic changes on intrauterine fetal growth in normal gestation and gestation complicated by diabetes. Postepy Hig Med Dosw. (online), 2005;59:490-495.
37. HAPO Study Cooperative Research Group, Metzger BE, Lowe LP, Dyer AR, Trimble ER, Chaovarindr $U$ et al. Hyperglycemia and adverse pregnancy outcomes. N Engl J Med. 2008;358:1991-2002. Doi: 10.1056/NEJMoa0707943

38. Murphy HR, Bell R, Cartwright C, Curnow P, Maresh M, Morgan M. et al. Improved pregnancy outcomes in women with type 1 and type 2 diabetes but substantial clinic-to-clinic variations: a prospective nationwide study. Diabetologia. 2017;60(9):1668-1677. Doi: 10.1007/s00125-017-4314-3

39. Wilczyński J., Dziatosz K. [Gestational diabetes mellitus and associated risks for mother and child.] Perinat Neonat Gin 2009;2: 85-89.

40.Zaręba-Szczudlik J, Romejko E, Ahmed S. [Fetal macrosomia as a clinical problem - recognition and management.] Perinat Neonat Gin. 2010;3:117-123.

41.Szymańska M, Bomba-Opoń DA, Celińska AM, Wielgoś M. Diagnostic of gestational diabetes mellitus and the prevalence of LGA (Large for Gestational Age). Ginekol Pol. 2008;79:177-181.

42.Gutaj P, Wender-Ożegowska E, Iciek R, Zawiejska A, Pietryga M, Brązert J. Maternal serum placental growth factor and fetal SGA in pregnancy complicated by type 1 diabetes mellitus. J Perinat Med. 2014;42(5):629-633. Doi: 10.1515/jpm-2013-0227

43.Adamkin DH. Neonatal hypoglycemia. Curr Opin Pediatr. 2016;28(2):150-155. Doi: 10.1097/MOP.0000000000000319

44.Thompson-Branch A, Havranek T. Neonatal hypoglycemia. Pediatr Rev. 2017;38(4):147-157. Doi: 10.1542/pir.2016-0063

45.Tin W. Defining neonatal hypoglycaemia: a continuing debate. Semin Fetal Neonatal Med. 2014;19(1):27-32. Doi: 10.1016/j. siny.2013.09.003

46. Harris DL, Battin MR, Weston PJ, Harding JE. Continuous glucose monitoring in newborn babies at risk of hypoglycemia. J Pediatr. 2010;157(2):198-202. Doi: 10.1016/j.jpeds.2010.02.003

47. Woo HC, Tolosa L, El-Metwally D, Viscardi RM. Glucose monitoring in neonates: need for accurate and non-invasive methods. Arch Dis Child Fetal Neonatal Ed. 2014;99(2):F153-F157. Doi: 10.1136/ archdischild-2013-304682

48.Bain E, Crane M, Tieu J, Han S, Crowther CA, Middleton P. Diet and exercise interventions for preventing gestational diabetes mellitus. Cochrane Database Syst Rev 2015;4:CD010443. Doi: 10.1002/14651858.CD010443

49. Koivusalo SB, Rönö K, Klemetti MM, Roine RP, Lindström J, Erkkola M, et al. Gestational diabetes mellitus can be prevented by lifestyle intervention: the Finnish Gestational Diabetes Prevention Study (RADIEL): a randomized controlled trial. Diabetes Care. 2016;39(1):24-30. Doi: 10.2337/dc15-0511 
50.Embaby H, Elsayed E, Fawzy M. Insulin Sensitivity and Plasma Glucose Response to Aerobic Exercise in Pregnant Women at Risk for Gestational Diabetes Mellitus. Ethiop J Health Sci. 2016;26(5):409414.

51. Mack LR, Tomich PG. Gestational Diabetes: Diagnosis, Classification, and Clinical Care. Obstet Gynecol Clin North Am. 2017;44(2):207217. Doi: $10.1016 /$ j.ogc.2017.02.002

52. Bowker SL, Savu A, Yeung RO, Johnson JA, Ryan EA, Kaul P. Patterns of glucose-lowering therapies and neonatal outcomes in the treatment of gestational diabetes in Canada. 2009-2014. Diabet Med. 2017;34(9):1296-1302. Doi: 10.1111/dme.13394

53. Farrar D, Tuffnell DJ, West J, West HM.. Continuous subcutaneous insulin infusion versus multiple daily injections of insulin for pregnant women with diabetes. Cochrane Database Syst Rev. 2016;(6):CD005542. Doi: 10.1002/14651858.CD005542

54.Wender-Ozegowska E, Zawiejska A, Ozegowska K, WroblewskaSeniuk K, Iciek R, Mantaj U. et al. Multiple daily injections of insulin versus continuous subcutaneous insulin infusion for pregnant women with type 1 diabetes. Aust NZ J Obstet Gynecol. 2013;53(2):130-135. Doi: 10.1111/ajo.12027
55.Actualisation of Polish Gyneacological Society Standards of Medical Care in management of women with diabetes. Ginekol Pol. 2014;85(6):476-478

56. Chobot AP, Otto-Buczkowska E. Glucose homeostasis from foetus through childhood. DDK/ECD. 2011;11(1):29-38.

57. Maayan-Metzger A, Lubin D, Kuint J. Hypoglycemia rates in the first days of life among term infants born to diabetic mothers. Neonatology. 2009;96(2):80-85. Doi: 10.1159/000203337

58.0tto-Buczkowska E. [Disorders glucose homeostasis in the neonates and young infants Part I. Hypoglycaemia.]. Perinatol Ginekol 2006;42:33-39.

59. Malinowska-Polubiec A, Sienko J, Lewandowski Z, Czajkowski K, Smolarczyk R. Risk factors of abnormal carbohydrate metabolism after pregnancy complicated by gestational diabetes mellitus. Gynecol Endocrinol. 2012;28(5):360-364. Doi: $10.3109 / 09513590.2011 .613963$

60.0tto-Buczkowska E. [Postpartum alterations blood glucose homeostasis]. Med Rodz 2014;17:23-26. 